\title{
CMEARTICLE
}

\section{Clinics in diagnostic imaging (192)}

Nicola Yan Ying Lee ${ }^{1}$, MBBS, Bak Siew Steven Wong ${ }^{1}$, MBChB, MMed
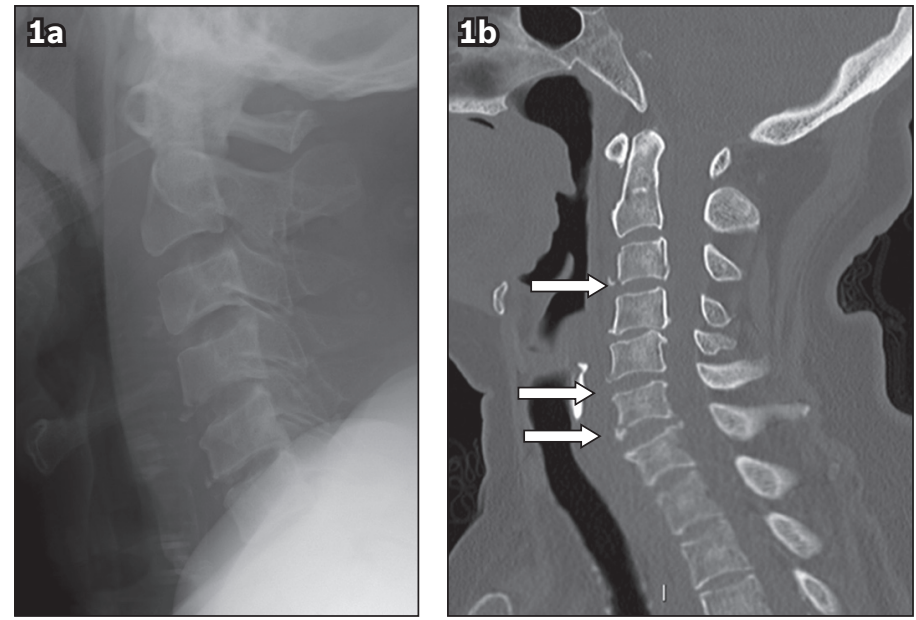

Fig. 1 (a) Plain lateral radiograph of the cervical spine. (b) Unenhanced sagittal CT image of the cervical spine in bone window.
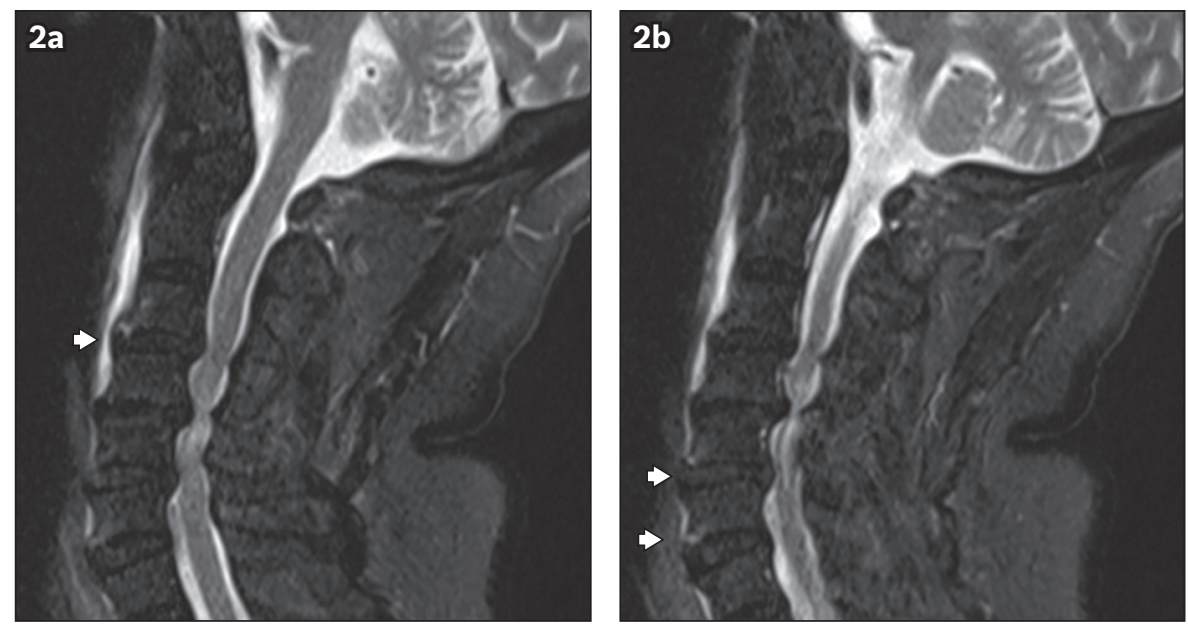

Fig. 2 Contiguous sagittal inversion recovery MR images of the cervical spine in (a) midline and (b) lateral view.

\section{CASE PRESENTATION}

An 82-year-old woman presented to the emergency department with complaints of neck pain and bilateral upper limb paraesthesia. She had sustained mild injury to the left knee and neck after an unwitnessed fall at home the day before. Physical examination revealed tenderness over the C4-6 region but no obvious step deformity. Neurological examination of the limbs was limited by pain. Plain radiography of the cervical spine showed thickening of the pre-vertebral soft tissue and age-related degenerative changes, but no apparent fracture was seen. Subsequent computed tomography (CT) and magnetic resonance (MR) imaging were performed. What do the images (Figs. 1 \& 2) show? What is the diagnosis? 


\section{IMAGE INTERPRETATION}

Lateral radiograph of the cervical spine (Fig. 1a) demonstrates small fractures of the anteroinferior endplates of the C4 and C5 vertebral bodies. Sagittal CT image of the cervical spine (Fig. 1b) shows similar fractures at the anteroinferior endplate corners of the C3, C5 and C6 vertebrae with focal kyphosis at these levels (arrows). The corresponding sagittal short T1 inversion recovery MR images (Fig. 2) confirm teardrop fractures at the anteroinferior corners of C3-6 (arrowheads) with focal high-intensity signals, indicative of marrow oedema. Associated disruption of the anterior longitudinal ligament is noted. There are also severe central spinal canal stenosis and spinal cord compression with post-compression oedema distally.

\section{DIAGNOSIS}

Flexion teardrop fracture (FTDF).

\section{CLINICAL COURSE}

The patient was not suitable for surgical intervention in view of her multiple comorbidities. Thus, she was managed conservatively with an Aspen collar and physiotherapy.

\section{DISCUSSION}

FTDF of the cervical spine, originally described by Kahn and Schneider in 1956, derives its name from the characteristic triangular bony fragment (resembling a drop of water) that separates from the anteroinferior endplate corner of the cervical vertebral body. ${ }^{(1)}$

FTDFs represent forced hyperflexion of the cervical spine and axial compression at the anterosuperior aspect of the vertebral body culminating in oblique coronal vertebral fractures, which occur most commonly at the C5 level and less frequently at the C4 and C6 levels. ${ }^{(2)}$ The involved vertebral body can be split coronally into two principal fragments. Associated retrolisthesis of the divided vertebral body into the spinal canal and disruption of the supporting ligaments result in marked instability at the level of injury. ${ }^{(3)}$ Consequently, this particular type of fracture has the highest risk of neurological injury among all cervical injuries. ${ }^{(4)}$ A majority of patients who present with FTDFs often have sustained high-energy traumatic injuries (e.g. from shallow water diving accidents and motor vehicle accidents), and a large number are quadriplegic at presentation..$^{(3)}$

Diagnosis of FTDFs in an acute trauma setting is problematic, as movement of the cervical spine is prohibited in patients with spinal injuries and physicians are unable to accurately predict such injuries based solely on history and physical examination. ${ }^{(5)}$ The combination of a potentially catastrophic injury and an inability to diagnose it clinically creates a conundrum, and herein lies the value of radiology.

Plain radiography is an excellent screening tool for cervical trauma in an acute setting when clinical suspicion is high. On the lateral view, the affected vertebral body is divided into two fragments: the anterior characteristic 'teardrop' fragment and the remaining posterior vertebral body. The anterior aspect of the anterior triangular fragment is, in most cases, aligned with that
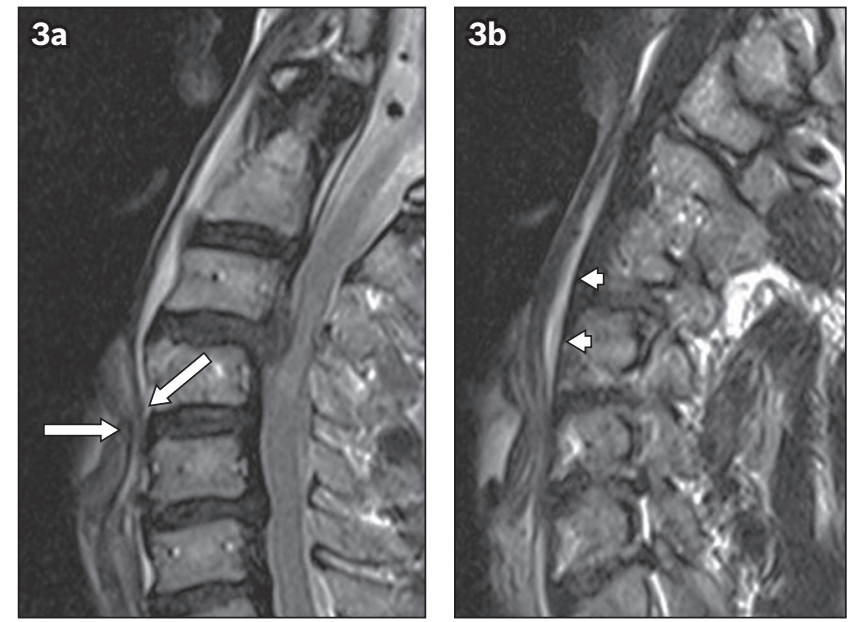

Fig. 3 (a \& b) Sagittal T2-W MR images of the cervical spine of a 64-year-old motor vehicular accident victim show disruption of the anterior longitudinal ligament as a result of a C4 flexion teardrop fracture (arrows denote the separate ends) with resultant pre-vertebral haematoma (arrowheads).

of the vertebral body below. A small proportion of these anterior fragments may be displaced beyond the anterior vertebral line. In all cases, however, the posteroinferior aspect of the posterior vertebral body fragment is displaced dorsally beyond the posterior vertebral line to varying degrees in relation to the vertebral body below.

Depending on the degree of subluxation of both fracture fragments, characteristic disruption of the supporting anterior and posterior ligamentous structures is seen. Consequential instability results in kyphotic deformity of the cervical spine at the level of injury. A study by Fuentes et al found that in cases where the kyphotic deformity is greater than $20^{\circ}$, there is often accompanying tetraplegia or anterior spinal cord injury. ${ }^{(6)}$

A series of compressive flexion injuries compiled and grouped into increasingly severe stages based on radiographic features by Allen et al indicates that the incidence of spinal cord injury ranged from $0 \%$ in the mildest category to $100 \%$ in the most severe. ${ }^{(7)}$ Kim et al attempted to correlate radiographic features with neurological status and found similar results: $97 \%$ of cases exhibited neurological deficits in the setting of sagittal body or laminar fractures. ${ }^{(8)}$

CT (Fig. 3) allows for three-dimensional analysis and provides better soft tissue contrast as compared to plain radiography. It is often an essential imaging tool in the assessment of FTDFs, as it provides precise delineation of the fracture anatomy. CT also provides overall visualisation of the central spinal canal and any impingement of the spinal cord by extradural sources. Alteration of window level and width also allows for some delineation of soft tissue structures.

MR imaging is considered the gold standard in assessing the extent of injury to the spinal cord in blunt trauma. ${ }^{(9)}$ Labattaglia et al suggested that the detection of MR abnormalities should determine changes to subsequent management. ${ }^{(10)}$ Although MR imaging does not add significant value in the detection of unstable osseous injury that is not already evident on plain radiography or $\mathrm{CT},{ }^{(10)}$ it is often employed in severe trauma due to its superior characterisation of injury to soft tissue structures, including 

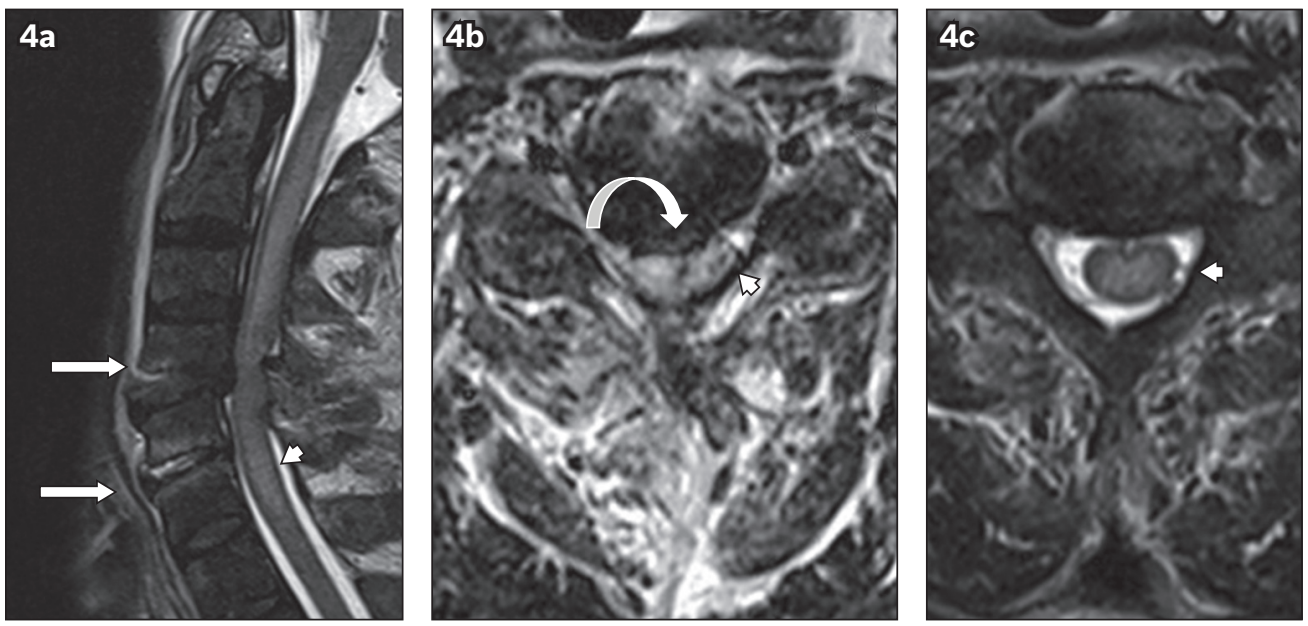

Fig. 4 (a) Sagittal T2-W and (b \& c) axial MR images of the cervical spine of a 67-year-old man after an unwitnessed fall. As a result of a C4 flexion teardrop fracture, there is disruption of the anterior longitudinal ligament at C4-5 and C5-6 with periligamentous oedema and fluid tracking into the exposed intervertebral disc spaces (arrows). Heterogeneity and raised signal of the interspinous ligaments at these levels indicates associated injury. Compression of the spinal cord at the C5 level (curved arrow) secondary to the C4/C5 retrolisthesis with resultant cord oedema (arrowheads) is seen.

pre- and paravertebral haematoma, supporting ligamentous disruption, post-traumatic intervertebral disc herniation, cord oedema and cord compression (Fig. 4). ${ }^{(11)}$

Analysis of the cervical spine fracture mechanism often requires understanding of radiographic appearances that characterise the end result of trauma. Careful correlation with clinical history and physical examination is therefore necessary due to the imaging similarities between FTDFs and other cervical injuries. Despite the recognised radiological features of FTDFs, diagnostic confusion may still arise between FTDFs and other types of cervical fractures with triangular fragments. For example, a hyperextension injury may produce an avulsed bony fragment at the anteroinferior corner of a vertebral body and disruption of the anterior longitudinal ligament, both of which appear similar to an FTDF. Distractive flexion injuries with sufficient axial compression may likewise produce equally misleading features. ${ }^{(3)}$ Therefore, it is crucial to consider the clinical history, including injury mechanism and position of neck during such injury, in the evaluation of cervical spine trauma imaging, as shown by the Allen and Ferguson Classification. ${ }^{(7)}$

The main aims of treatment are to alleviate or reduce the risk of neurological deficit and to restore alignment of the cervical spine. Due to the inherent instability of FTDFs, surgery is the mainstay of management. Widely accepted surgical management for FTDFs includes complete excision of the affected vertebral body (corpectomy) with subsequent anterior cervical plate insertion. Fisher et al compared the outcomes of patients with unstable FTDFs who undergo surgery versus those who were managed conservatively (with thoracic halo vest), and found that surgical management is far superior in re-establishing and maintaining sagittal alignment of the cervical spine. This is further exemplified by the fact that $17 \%$ of patients who received conservative management initially went on to have operative treatment subsequently. ${ }^{(12)}$ Another study by Kim et al found similar results and also demonstrated improvement in neurological status in those who received surgery. ${ }^{(13)}$

\section{CONCLUSION}

FTDFs are traumatic injuries to the cervical spine resulting from flexion-compression forces, and carry significant risk of bony instability and potential neurological damage. Imaging is indispensable for prompt diagnosis, and advanced imaging such as MR imaging is particularly advantageous in the identification of neurological injury. Nonetheless, careful correlation of radiological clues with clinical findings is needed - given the possible imaging similarities between FTDFs and other cervical injuries - to positively influence patient management and outcome.

ABSTRACT An 82-year-old woman presented with neck pain and bilateral upper limb paraesthesia after sustaining an unwitnessed fall at home the day before. Physical examination revealed tenderness over the C4-6 region but no evidence of step deformity or neurological deficit. Magnetic resonance imaging of the cervical spine revealed multiple small fractures at the anteroinferior endplate corners of the C3, C5 and C6 vertebrae with focal kyphosis and marrow oedema at these levels, as well as associated disruption of the anterior longitudinal ligament and central spinal canal stenosis. The diagnosis of multiple flexion teardrop fractures was made based on these imaging findings, and the patient subsequently received conservative management. This paper illustrates the radiological features of flexion teardrop fractures and highlights the importance of prompt diagnosis and management of such cases.

Keywords: cervical spine injury, flexion teardrop fracture, magnetic resonance imaging, vertebral fracture

\section{REFERENCES}

1. Kahn EA, Schneider RC. Chronic neurological sequelae of acute trauma to the spine and spinal cord. I. The significance of the acute-flexion or tear-drop fracturedislocation of the cervical spine. J Bone Joint Surg Am 1956; 38-A:985-97.

2. el-Khoury GY, Kathol MH, Daniel WW. Imaging of acute injuries of the cervical spine: value of plain radiography, CT, and MR imaging. AJR Am J Roentgenol $1995 ; 164: 43-50$ 
3. Lee C, Kim KS, Rogers LF. Triangular cervical vertebral body fractures: diagnostic significance. AJR Am J Roentgenol 1982; 138:1123-32.

4. Raniga SB, Menon V, Al Muzahmi KS, Butt S. MDCT of acute subaxial cervical spine trauma: a mechanism-based approach. Insights Imaging 2014; 5:321-38.

5. Jacobs LM, Schwartz R. Prospective analysis of acute cervical spine injury: a methodology to predict injury. Ann Emerg Med 1986; 15:44-9.

6. Fuentes JM, Bloncourt J, Vlahovitch B, Castan P. [Tear drop fractures. Contribution to the study of the mechanism of osteo-disco-ligamentous lesions] Neurochirurgie 1983; 29:129-34. French.

7. Allen BL Jr, Ferguson RL, Lehmann TR, O'Brien RP. A mechanistic classification of closed, indirect fractures and dislocation of the lower cervical spine. Spine (Phila Pa 1976) 1982; 7:1-27.

8. Kim KS, Chen HH, Russell EJ, Rogers LF. Flexion teardrop fracture of the cervica spine: radiographic characteristics. AJR Am J Roentgenol 1989; 152:319-26.
9. Raza M, Elkhodair S, Zaheer A, Yousaf S. Safe cervical spine clearance in adult obtunded blunt trauma patients on the basis of a normal multidetector CT scan-a meta-analysis and cohort study. Injury 2013; 44:1589-95.

10. Labattaglia MP, Cameron PA, Santamaria M, et al. Clinical outcomes of magnetic resonance imaging in blunt cervical trauma. Emerg Med Australas 2007; 19:253-61.

11. Katzberg RW, Benedetti PF, Drake CM, et al. Acute cervical spine injuries: prospective MR imaging assessment at a level 1 trauma center. Radiology 1999; 213:203-12.

12. Fisher CG, Dvorak MF, Leith J, Wing PC. Comparison of outcomes for unstable lower cervical flexion teardrop fractures managed with halo thoracic vest versus anterior corpectomy and plating. Spine (Phila Pa 1976) 2002; 27:160-6.

13. Kim HJ, Lee KY, Kim WC. Treatment outcome of cervical tear drop fracture. Asian Spine J 2009; 3:73-9. 


\section{SINGAPORE MEDICAL COUNCIL CATEGORY 3B CME PROGRAMME} (Code SMJ 201811A)

Question 1. Regarding the location of a flexion teardrop fracture (FTDF):

(a) It is typically at the atlanto-axial joint.

(b) It is most common in the cervical spine at the $\mathrm{C} 5$ level.

(c) It is most common in the cervical spine at the C4 and C6 levels.

(d) It involves the thoracolumbar spine.

Question 2. Regarding the characteristic mechanism of injury of an FTDF:

(a) It is the result of a flexion-compression injury.

(b) It is the result of a flexion-distraction injury.

(c) It is caused by hyperextension of the spine.

(d) It is a rotational injury of the spine.

Question 3. Regarding the classical imaging findings of an FTDF:

(a) There is usually a vertebral body compression fracture.

(b) There is anterolisthesis of consecutive vertebrae.

(c) There is disruption of the anterior longitudinal ligament.

(d) There is a Gibbus deformity of the thoracolumbar spine.

Question 4. Regarding the best modality for delineation of spinal cord injury:

(a) Plain radiography alone is sufficient.

(b) Computed tomography provides the best soft tissue contrast.

(c) Magnetic resonance imaging is the best imaging modality, as it allows for the assessment of the spinal cord and soft tissue injuries.

(d) Ultrasonography allows for the assessment of superficial haematomas.

Question 5. The following is the mainstay of treatment for FTDFs:

(a) Physiotherapy only.

(b) Physiotherapy and appropriate analgesia.

(c) Prompt application of a thoracic halo vest only.

(d) Surgical intervention.

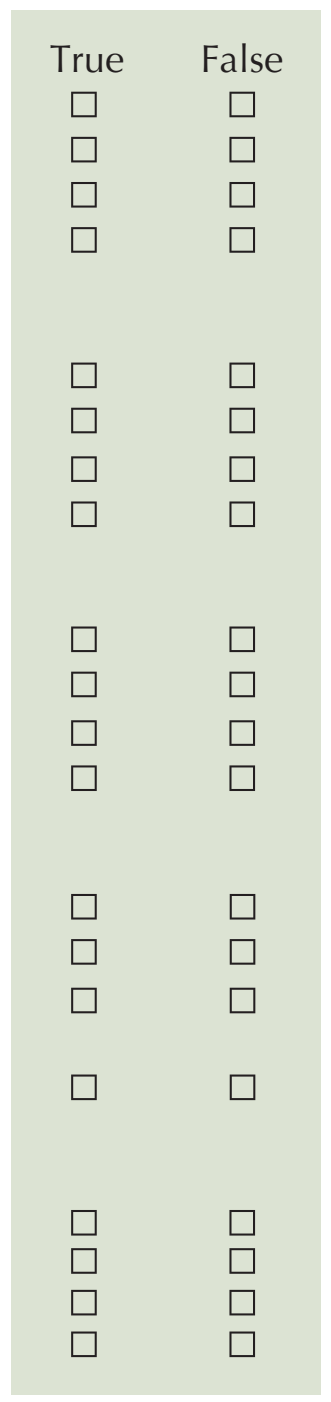

\section{Doctor's particulars:}

Name in full:

MCR no.:

Specialty:

Email:

\footnotetext{
SUBMISSION INSTRUCTIONS:

Visit the SMJ website: http://www.smj.org.sg/current-issue and select the appropriate quiz. You will be redirected to the SMA login page.

For SMA member: (1) Log in with your username and password (if you do not know your password, please click on 'Forgot your password?'). (2) Select your answers for each quiz and click 'Submit'.

For non-SMA member: (1) Create an SMJ CME account, or log in with your SMJ CME username and password (for returning users). (2) Make payment of SGD 21.40 (inclusive of $7 \%$ GST) via PayPal to access this month's quizzes. (3) Select your answers for each quiz and click 'Submit'.

RESULTS:

(1) Answers will be published online in the SMJ January 2019 issue. (2) The MCR numbers of successful candidates will be posted online at the SMJ website by 3 January 2019. (3) Passing mark is $60 \%$. No mark will be deducted for incorrect answers. (4) The SMJ editorial office will submit the list of successful candidates to the Singapore Medical Council. (5) One CME point is awarded for successful candidates. (6) SMC credits CME points according to the month of publication of the CME article (i.e. points awarded for a quiz published in the December 2017 issue will be credited for the month of December 2017, even if the deadline is in January 2018),

Deadline for submission (November 2018 SMJ 3B CME programme): 12 noon, 27 December 2018.
} 